\title{
The Electrogenic Sodium Bicarbonate Cotransporter: Developmental Expression in Rat Brain and Possible Role in Acid Vulnerability
}

\author{
Rona G. Giffard, ${ }^{1}$ Marios C. Papadopoulos, ${ }^{1}$ Johannes A. van Hooft, ${ }^{2}$ Lijun Xu, ${ }^{1}$ Raffaela Giuffrida, ${ }^{2}$ and \\ Hannah Monyer ${ }^{2}$ \\ ${ }^{1}$ Department of Anesthesia, Stanford University, Stanford, California 94305-5117, and 2Zentrum fuer Molekulare Biologie \\ Heidelberg, University of Heidelberg, D69120 Heidelberg, Germany
}

\begin{abstract}
The electrogenic sodium bicarbonate cotransporter (NBC) is expressed in glial cells in the brain and plays an important role in the regulation of both intracellular and extracellular $\mathrm{pH}$. Differential vulnerability to acidosis between neurons and glia has been noted and may contribute to infarction after cerebral ischemia. Ionic substitution studies and inhibition of injury by 4,4'-di-isothiocyanostilbene-2,2'-disulfonic acid suggest that $\mathrm{NBC}$ is involved in astrocyte vulnerability to acidic injury. Recently two NBC cDNAs differing in 5'-untranslated and $\mathrm{N}$-terminal coding sequence have been cloned from kidney and pancreas. We cloned one of these cDNAs from rat brain and demonstrate here that the clone is functional by expression in Xenopus oocytes. We determined the developmental and regional expression of NBC in the brain by in situ hybridization. Expression was observed in the spinal cord at embryonic day
\end{abstract}

17, whereas expression in brain was first seen at approximately postnatal day 0 (P0), increased at $\mathrm{P} 15$, and persisted in the adult brain. Expression was widespread throughout the cerebellum, cortex, olfactory bulb, and subcortical structures. Cellular resolution of the in situ hybridization signal and double labeling for glial fibrillary acidic protein were consistent with a glial localization for NBC. Expression of NBC in 3T3 cells that do not normally express this transporter rendered them vulnerable to acid injury. The expression profile suggests that this transporter is critical during the later stages of brain development and could be one of the factors contributing to the different patterns of injury seen in perinatal versus adult cerebral ischemia.

Key words: bicarbonate transport; $\mathrm{pH}$ regulation; development; glial cells; splice variant; acid injury; ischemia
The electrogenic sodium bicarbonate cotransporter (NBC) has been studied extensively in glial cells from both invertebrates and vertebrates and from different brain regions (Deitmer and Schlue, 1989; Newman, 1991; O'Connor et al., 1994). The extracellular $\mathrm{pH}$ is an important determinant of neuronal excitability (Ransom, 1992). During physiological activation of neurons a shift to acidic pH occurs (Trapp et al., 1996), and modulation of the extracellular $\mathrm{pH}$ by astrocytes may be critical to setting the level of excitability of neurons (Ransom, 1992). During neuronal activity extracellular potassium increases, leading to glial depolarization and activation of the cotransporter (O'Connor et al., 1994). With activation of $\mathrm{NBC}$ the extracellular $\mathrm{pH}$ is acidified, while the intracellular $\mathrm{pH}$ of the astrocyte is alkalinized. The extracellular acidification may be instrumental in regulating local brain blood flow (Newman, 1991) in addition to its effect on neuronal excitability. This transporter plays an important role in physiological

\footnotetext{
Received Aug. 16, 1999; revised Oct. 18, 1999; accepted Nov. 4, 1999.

This work was supported in part by Boehringer Ingelheim and the Schilling Foundation (H.M.), sabbatical leave (R.G.G.), National Institutes of Health Grant GM 49831 (R.G.G.), and a NATO Science Fellowship (J.A.v.H.). We thank Ulla Amtmann for expert technical assistance, Walter Boron for the anti-NBC antibody, and Peter Seeburg for helpful discussions. The GenBank accession number for NBC is AF210250.

Correspondence should be addressed to Dr. Rona Giffard, Department of Anesthesia, S272, Stanford University School of Medicine, Stanford, CA 94305-5117. E-mail: rona.giffard@stanford.edu.

Dr. van Hooft's present address: Institute of Neurobiology, University of Amsterdam, Kruislaan 320, NL-1098 SM Amsterdam, The Netherlands.

Dr. Papadopoulos's present address: Neurosurgery, Atkinson Morley's Hospital, Wimbledon, London SW20 0NE, United Kingdom.

Copyright (C) 2000 Society for Neuroscience $0270-6474 / 00 / 201001-08 \$ 15.00 / 0$
}

$\mathrm{pH}$ regulation and may play a critical role in $\mathrm{pH}$ regulation during pathophysiological events, such as brain ischemia (Lascola and Kraig, 1997).

Cerebral ischemia is associated with a fall in intracellular and extracellular pH (Kraig et al., 1986), and more severe acidosis correlates with more severe injury (Myers and Yamaguchi, 1977). However, in vitro, acidosis in the range seen in ischemia protects neurons from ischemia-like injury (Schurr et al., 1988; Giffard et al., 1990a; Tombaugh and Sapolsky, 1990) and attenuates glutamate-induced neuronal death (Giffard et al., 1990a). Surprisingly, astrocytes in vitro were more vulnerable to extracellular acidity-mediated injury than were neurons (Giffard et al., 1990b). Protection from hypoxic injury by acidity has been observed not only in neurons (Schurr et al., 1988; Giffard et al., 1990a) but also in cardiac (Bing et al., 1973), renal (Pentilla and Trump, 1974), and liver cells (Currin et al., 1991). A large body of work now supports the protective effect of inhibiting the sodium hydrogen exchanger in the setting of myocardial ischemia (for review, see Karmazyn, 1998). The observed enhanced functional recovery seems to be caused by slower recovery from intracellular acidosis after reperfusion (Koike et al., 1996). Furthermore, inhibition of intracellular alkalinization by inhibiting bicarbonate transport with 4,4'-di-isothiocyanostilbene-2,2'-disulfonic acid (DIDS) also improved functional myocardial recovery (Meiltz et al., 1998).

Recently NBC cDNA has been cloned from several species (Romero and Boron, 1999), from kidney (Romero et al., 1997, 1998), and from pancreas (Abuladze et al., 1998) and found to occur in two forms that differ in $5^{\prime}$-untranslated and $\mathrm{N}$-terminal coding sequence. As judged from its sequence, $\mathrm{NBC}$ is a member 
of the bicarbonate transporter superfamily that also includes the anion exchangers AE1-3 (Kopito, 1990). We cloned a cDNA for $\mathrm{NBC}$ from rat brain and performed in situ hybridization studies to determine the time course and regional distribution of $\mathrm{NBC}$ expression in brain. A possible role for NBC in astrocyte acidinduced injury was found in the ionic dependence of the injury, its inhibition by DIDS, and the conversion of 3 T3 cells from acid resistant to acid sensitive by overexpression of NBC cDNA.

\section{MATERIALS AND METHODS}

Primary cultures. Primary astrocyte cultures from the neocortex of newborn (postnatal day 1-2) Swiss-Webster mice were prepared as described previously (Dugan et al., 1995) and used after $25 \mathrm{~d}$ in vitro. All procedures were performed according to a protocol approved by the Stanford animal care and use committee in compliance with the National Institutes of Health guidelines. Dissociated neocortical cells were plated in $15 \mathrm{~mm}$ Falcon Primaria 24-well plates at one to two hemispheres/plate.

Balanced salt solutions. Cells were washed into balanced salt solutions $\left(\mathrm{BSS}_{5.5}\right)$ with the following compositions: $5.5 \mathrm{~mm}$ glucose at $\mathrm{pH} 6.8$ or 7.4 containing $\mathrm{NaCl}$ (117.9 mM for $\mathrm{pH} 7.4 ; 128.9 \mathrm{~mm}$ for $\mathrm{pH} 6.8), \mathrm{KCl}(5.4$ $\mathrm{mm}), \mathrm{MgSO}_{4}(0.8 \mathrm{~mm}), \mathrm{NaH}_{2} \mathrm{PO}_{4}(1 \mathrm{~mm}), \mathrm{CaCl}_{2}(1.8 \mathrm{~mm}), \mathrm{HEPES}$ for $\mathrm{pH} 7.4$ or 1,4-piperazinediethanesulphonic acid (PIPES) for $\mathrm{pH} 6.8$ (10 $\mathrm{mm})$, and phenol red $(10 \mathrm{mg} / \mathrm{l})$. After adjusting the $\mathrm{pH}$ to 7.4 or $6.8 \mathrm{with}$ $\mathrm{NaOH}, \mathrm{NaHCO}_{3}$ was added $(14.7 \mathrm{~mm}$ for $\mathrm{pH} 7.4 ; 3.7 \mathrm{~mm}$ for $\mathrm{pH} 6.8)$ to maintain the $\mathrm{pH}$ in a $5 \% \mathrm{CO}_{2}$ atmosphere at $37^{\circ} \mathrm{C}$. Nominally $\mathrm{HCO}_{3}{ }^{-}$free $\mathrm{BSS}_{5.5}$ was made by replacing the $\mathrm{NaHCO}_{3}{ }^{-}$with $\mathrm{NaCl}$, and experiments were performed at $37^{\circ} \mathrm{C}$ in room air or nitrogen for hypoxic experiments. Reduced-Na ${ }^{+} \mathrm{BSS}_{5.5}$ was prepared by replacing $\mathrm{NaCl}$ with choline-Cl (Sigma, St. Louis, MO). Control experiments showed that astrocyte cultures were not injured by incubation in the substituted $\mathrm{BSS}_{5.5}$ solutions at $\mathrm{pH} 7.4$ for $>24 \mathrm{hr}$.

Injury paradigms. For acidosis injury, cultures were washed into the indicated solutions at $\mathrm{pH} 6.8$ and maintained at $37^{\circ} \mathrm{C}$ in a humidified incubator for $24 \mathrm{hr}$. Injury was assessed by measuring lactate dehydrogenase $(\mathrm{LDH})$ released by the cells (Koh and Choi, 1987) or after staining with trypan blue and cell counting. For combined oxygenglucose deprivation, astrocyte cultures were washed into balanced salt solution lacking glucose $\left(\mathrm{BSS}_{0}\right)$ that was equilibrated previously with the $5 \% \mathrm{CO}_{2}, 10 \% \mathrm{H}_{2}$, and $85 \% \mathrm{~N}_{2}$ atmosphere in the anoxia chamber (Forma Scientific) and incubated at $37^{\circ} \mathrm{C}$ in the anoxia chamber for $6 \mathrm{hr}$. When nominally bicarbonate-free buffer was used, the atmosphere was $100 \% \mathrm{~N}_{2}$. Oxygen-glucose deprivation was terminated by washing the cultures into oxygenated $\mathrm{BSS}_{5.5}$ at $\mathrm{pH}$ 7.4. Cultures were kept in the normoxic incubator for $24 \mathrm{hr}$ before assessing injury. Maximum LDH release corresponding to death of all the cells was determined at the end of each experiment after freezing at $-70^{\circ} \mathrm{C}$ and rapid thawing. Because DIDS was found to interfere with the LDH assay, the extent of injury was quantitated by trypan blue or propidium iodide staining and cell counting of five $200 \times$ microscope fields for each culture. The number of stained cells was divided by the total number of cells in the field and expressed as a percentage. Between 1000 and 1500 cells were counted per culture.

Measurement of intracellular $\mathrm{pH}$. Intracellular $\mathrm{pH}\left(\mathrm{pH}_{\mathrm{i}}\right)$ was measured in populations of astrocytes with $2^{\prime}, 7^{\prime}$-bis-[2-carboxyethyl]-5-(-6) carboxyfluorescein (BCECF) using a modification of published methods (Mellergard et al., 1994). Primary astrocyte cultures were loaded with the membrane-permeable AM of BCECF at $6 \mu \mathrm{M}$ in $\mathrm{BSS}_{5.5}, \mathrm{pH} 7.4$, for 1-2 hr. The cells were then incubated in the appropriate $\mathrm{BSS}_{5.5}$ without additional BCECF AM for $3 \mathrm{hr}$ and were suspended in $1.5 \mathrm{ml}$ of $\mathrm{BSS}_{5.5}$ of the same composition. Fluorescence intensity was measured immediately at excitation $490 \mathrm{~nm}$ and emission $535 \mathrm{~nm}\left(\mathrm{I}_{1}\right)$ and excitation $440 \mathrm{~nm}$ and emission $535 \mathrm{~nm}\left(\mathrm{I}_{2}\right)$, and the $\mathrm{pH}_{\mathrm{i}}$ of astrocytes was determined from a standard curve of $\mathrm{I}_{1} / \mathrm{I}_{2}$ versus $\mathrm{pH}_{\mathrm{i}}$. The standard curve was obtained by exposing astrocytes, loaded with BCECF AM as described, to solutions of different pHs in which $100 \mathrm{~mm} \mathrm{NaCl}$ was replaced with $100 \mathrm{~mm} \mathrm{KCl}$ with the $\mathrm{K}^{+}$ionophore nigericin $(2.8 \mu \mathrm{M}$ final concentration) added 5 min before each measurement.

Hippocampal cDNA library screening. A brain hippocampal cDNA library made from postnatal day 15 rat was screened with an oligonucleotide probe (5'-ATACGTTCTGCGGCCGGGGAGACTGCAGAAGTGAAAATACTGT-3') based on the human NBC cDNA cloned from kidney (Burnham et al., 1997) and with a PCR-amplified 1093 bp DNA fragment amplified from rat brain cDNA using two primers from the human sequence $\left(5^{\prime}\right.$ -
AACATGCAGGGGTGTTGGAGAG-3' and 5'-GTCTCTGTCTCCATCTTCA-3'). The human sequence was used because at the time these experiments were begun the rat kidney sequence was not yet in the database. After plaque purification two putative full-length cDNA clones were identified.

Functional expression in oocytes. The NBC sequence obtained from the brain cDNA library screen was subcloned into a eukaryotic expression plasmid under the control of the cytomegalovirus (CMV) promoter for expression studies. The recombinant vector was dissolved at $2 \mathrm{mg} / \mathrm{ml}$ in distilled water and injected $(\sim 13 \mathrm{nl} /$ oocyte) into the nucleus of stage V-VI oocytes (Zwart et al., 1995). After 3 d, ion currents were recorded by conventional two microelectrode voltage clamp. Microelectrodes (smaller than $1 \mathrm{MOhm}$ ) were filled with $3 \mathrm{M} \mathrm{KCl}$. Oocytes were continuously superfused with external solution containing (in $\mathrm{mM}$ ): $\mathrm{NaCl}$ (130), $\mathrm{CaCl} 2$ (2), and HEPES (10), $\mathrm{pH}$ 7.3. Ion currents were evoked by switching to external solution in which $\mathrm{NaHCO}_{3}$ replaced equimolar $\mathrm{NaCl}$. For experiments under low- $\mathrm{Na}^{+}$conditions, $\mathrm{NaCl}$ was replaced by $N$-methyl-D-glucamine-Cl. The membrane potential was held at $-60 \mathrm{mV}$. Ion currents were recorded on a chart recorder.

Amplification of brain- or kidney-specific fragments. PCR conditions were $94^{\circ} \mathrm{C}$ for $3 \mathrm{~min}, 35 \mathrm{cycles}$ of $94^{\circ} \mathrm{C}$ for $30 \mathrm{sec}, 60^{\circ} \mathrm{C}$ for $30 \mathrm{sec}$, and $72^{\circ} \mathrm{C}$ for $40 \mathrm{sec}$, with a final incubation at $72^{\circ} \mathrm{C}$ for $10 \mathrm{~min}$. The sense oligonucleotide used to amplify a kidney-specific $5^{\prime}$ sequence was $5^{\prime}$ CACAGTTTGGCTCCCAGGCAC-3'. The sense oligonucleotide specific for the brain sequence was 5'-CAAACTGGAGGAGCGACGGAAG-3'; the common antisense oligonucleotide was 5'-GGAGGTGCTGGGCTGTCATC-3'. The predicted amplicons were 258 bp for the kidney sequence and $372 \mathrm{bp}$ for the brain sequence. RNA was isolated using the RNeasy kit (Qiagen, Hilden, Germany) from rat brain, kidney, colon, and small intestine, which had been frozen on dry ice immediately after removal. cDNA was synthesized from equal amounts of tissue-specific RNAs using random hexamers. Equal amounts of cDNA were then used as templates for the PCR reactions.

In situ hybridization. In situ hybridization was performed as described previously (Monyer et al., 1991). Rats of the indicated ages were anesthetized with halothane and killed by decapitation. Brains were rapidly removed and frozen on dry ice. Frozen sections $(15 \mu \mathrm{m})$ were cut on a cryostat, thaw-mounted on poly-L-lysine-coated slides, and dried at room temperature. After fixation in $4 \%$ paraformaldehyde $\left(4^{\circ} \mathrm{C}\right)$ for $5 \mathrm{~min}$, sections were washed in PBS, dehydrated in $100 \%$ ethanol, and stored in $100 \%$ ethanol $\left(4^{\circ} \mathrm{C}\right)$ until use. Just before hybridization, sections were air-dried. The oligonucleotide probe 5'-CCCACGAGCTTTCCTCCAATTTCACACACTCTTTCTTTGAC-3' was labeled with $\alpha{ }^{-35} \mathrm{~S}$ dATP $(1200 \mathrm{Ci} / \mathrm{mmol}$; Amersham, Arlington Heights, IL) using terminal deoxynucleotide transferase (BRL, Bethesda, MD). Labeled probe was dissolved in hybridization buffer at $1 \mathrm{pg} / \mathrm{ml}, 1000 \mathrm{dpm} / \mathrm{ml}$, and applied to sections. Controls were performed by adding 200 -fold excess of unlabeled oligonucleotide to demonstrate the specificity of the signal. Hybridization buffer consisted of $50 \%$ formamide $(\mathrm{v} / \mathrm{v}), 4 \times \mathrm{SSC}(1 \times \mathrm{SSC}, 0.15 \mathrm{M}$ $\mathrm{NaCl}$ and $0.015 \mathrm{M} \mathrm{Na}$ citrate), and $10 \%$ dextran sulfate (w/v). Hybridization was performed overnight at $42^{\circ} \mathrm{C}$, under parafilm coverslips. Sections were washed at a final stringency of $1 \times \mathrm{SSC}$ at $60^{\circ} \mathrm{C}$ for $20 \mathrm{~min}$ before dehydration and exposure to Kodak XOMAT film. Exposure time was $21 \mathrm{~d}$ at room temperature. To obtain cellular resolution, sections were dipped in Ilford $\mathrm{K} 5$ emulsion and exposed at $4{ }^{\circ} \mathrm{C}$ for 6 weeks. After development, slides were counterstained with $0.1 \%$ thionin and viewed with a Zeiss axioplan microscope. All slices were emulsiondipped, and the experiment was performed at least three times for each developmental time point.

Combined in situ hybridization and immunocytochemistry. In situ hybridization histochemistry was performed with antisense cRNA for NBC. A 355 bp DNA fragment of the rat brain NBC sequence beginning at the translational start codon was obtained by PCR from the cloned brain NBC cDNA and was subcloned into pBluescript SK (Stratagene, La Jolla, CA). The recombinant plasmid was linearized and transcribed with T3 RNA polymerase (Boehringer Mannheim, Indianapolis, IN). In vitro transcription, digoxigenin labeling of the riboprobe, and nonradioactive in situ hybridization with the riboprobe were performed as described previously (Catania et al., 1995). After in situ hybridization, sections were immediately processed for immunocytochemistry (Catania et al., 1995). Sections were incubated overnight at $4^{\circ} \mathrm{C}$ with rabbit anti-GFAP antibody (1:500; Dako A/S, Glostrup, Denmark). On the following day, sections were washed three times with Tris-buffered saline and incubated for $2 \mathrm{hr}$ in goat anti-rabbit IgG-carboxymethylindocyanineconjugated secondary antibody (1:200; Jackson ImmunoResearch- 
Dianova, Hamburg, Germany). Subsequently, slices were mounted on slides and coverslipped in Mowiol medium.

Overexpression of NBC in $3 T 3$ cells. The rat brain cDNA for NBC was subcloned into LXSN, a retroviral vector backbone (Miller and Rosman, 1989). After selection and packaging in the 89-2 cell line (Mann et al., 1983), viral supernatants were collected and used to infect cultures of $3 \mathrm{~T} 3$ cells. Infection and selection of $3 \mathrm{~T} 3$ cells expressing NBC were performed as described previously (Papadopoulos et al., 1996). Stably transfected 3T3 cells expressing either NBC or the control gene $\beta$-galactosidase were then passaged further for experiments. Exposure to $\mathrm{pH} 6.8$ was performed in $\mathrm{BSS}_{5.5}$ as noted above.

Immunoblot. Westerns were performed as described previously (Papadopoulos et al., 1996) except using a 7.5\% separating gel. The rabbit polyclonal antibody KIA was kindly provided by Dr. Walter Boron (Yale University). The antibody was used at a 1:1000 dilution in PBS containing $5 \%$ fetal bovine serum and $0.09 \% \mathrm{NaN}_{3}$.

\section{RESULTS}

\section{Astrocyte acid vulnerability}

The vulnerability of astrocytes to injury by exposure to $\mathrm{pH} 6.8$ for $24 \mathrm{hr}$ was determined alone or in combination with oxygenglucose deprivation for $6 \mathrm{hr}$ followed by reperfusion to simulate ischemic conditions. This $\mathrm{pH}$ is the value reported in normoglycemic, ischemic rat brain (Kraig et al., 1986). The ionic dependence and pharmacology of acid-induced injury and combined oxygen-glucose-acidic injury were compared (Fig. 1). Acidinduced injury was reduced from $>80 \%$ cell death to $<10 \%$ by substitution for extracellular bicarbonate, by reduction of sodium, or in the presence of DIDS, which blocks NBC (Romero and Boron, 1999). Blocking the sodium hydrogen exchanger with amiloride was ineffective. The ionic dependence of combined oxygen-glucose-acidic injury was similar to that for acid injury alone. Interestingly, when sodium is reduced the extent of injury from hypoxia or oxygen-glucose deprivation is significantly less at $\mathrm{pH} 6.8$ than at $\mathrm{pH} 7.4$, reminiscent of previous findings for neurons (Schurr et al., 1988, 1997; Giffard et al., 1990a; Tombaugh and Sapolsky, 1990) and other cell types. The ionic dependence and pharmacological response are consistent with a role for the sodium bicarbonate cotransporter in these two injury paradigms.

Acute reduction of bicarbonate in the extracellular buffer with $\mathrm{pH}$ reduction has been shown to induce the sodium bicarbonate cotransporter to run in the outward direction (Munsch and Deitmer, 1994). Although this is also likely to have occurred in our cultures, in the case of prolonged exposure to $\mathrm{pH} 6.8$ buffer conditions, a new bicarbonate gradient across the membrane would be established. If the cotransporter then returned to running in the inward direction, the intracellular $\mathrm{pH}$ would show a relative alkalinization. After a $3 \mathrm{hr}$ incubation at extracellular $\mathrm{pH}$ 6.8 in complete $\mathrm{BSS}_{5.5}$, the intracellular $\mathrm{pH}$ measured in astrocyte cultures in bicarbonate-containing buffer using BCECF was $6.73 \pm 0.01$, whereas the intracellular $\mathrm{pH}$ measured in the absence of bicarbonate was $6.54 \pm 0.04$ ( $n=12$; a statistically significant difference, $p<0.05)$. This result dissociates the degree of intracellular acidification from the extent of injury. The astrocytes incubated at $\mathrm{pH} 6.8$ without bicarbonate were not injured yet had a lower intracellular $\mathrm{pH}$ than did cultures incubated at $\mathrm{pH}$ 6.8 in the presence of bicarbonate. Whether the intracellular $\mathrm{pH}$ in cultures subjected to oxygen-glucose deprivation at $\mathrm{pH} 6.8$ was even lower than that observed when the only insult was to lower the $\mathrm{pH}$ is not known, because we were unable to measure intracellular $\mathrm{pH}$ while the cultures were anoxic.

\section{Identification of a brain variant of NBC cDNA}

We screened a postnatal day 15 (P15) rat brain hippocampal cDNA library with a probe based on the published kidney NBC
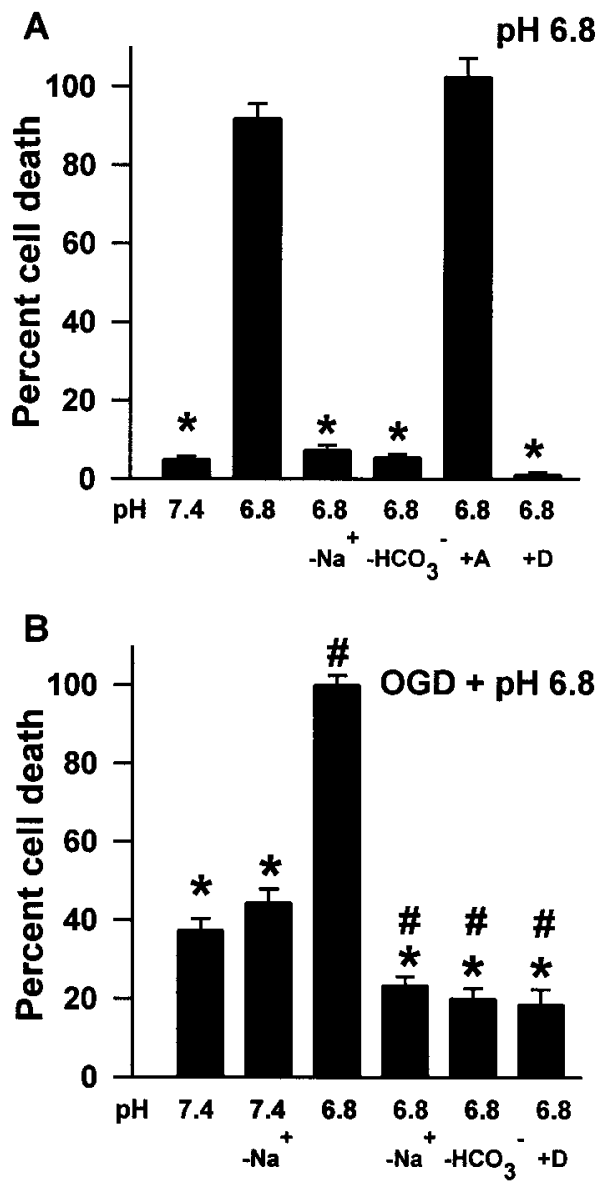

Figure 1. A, Astrocyte injury caused by acidosis alone requires extracellular $\mathrm{Na}^{+}$and $\mathrm{HCO}_{3}{ }^{-}$. Primary astrocyte cultures were kept in the indicated balanced salt solution $\left(\mathrm{BSS}_{5.5}\right)$ for $24 \mathrm{hr}$; then injury was quantitated by release of $\mathrm{LDH}$. Maximal $\mathrm{LDH}$ release was determined at the end of each experiment after freezing at $-70^{\circ} \mathrm{C}$ and rapid thawing. Cell death was determined by counting the number of cells staining with trypan blue, expressed as a percentage of the total cells counted for the +DIDS condition because DIDS interfered with the LDH assay. Exposure to $\mathrm{BSS}_{5.5}$ at $\mathrm{pH} 7.4$ or 6.8 was performed alone or with the addition of $0.1 \mathrm{~mm}$ amiloride or $1 \mathrm{~mm}$ DIDS $(6.8+A ; 6.8+D)$. Vertical bars represent means \pm SEM for $n=12$; $*$ denotes significant $(p<0.05)$ difference from $\mathrm{pH} 6.8$ by ANOVA and the Bonferroni test. $B$, Injury attributable to combined oxygen-glucose deprivation $(O G D)$ at $\mathrm{pH} 6.8$ has an ionic dependence similar to that of injury caused by acidosis alone. Primary astrocyte cultures were placed in an anoxic chamber and washed into the indicated $\mathrm{BSS}_{0}$ at $\mathrm{pH} 7.4$ or 6.8 , which had been equilibrated with anoxic gas. After $6 \mathrm{hr}$ the cultures were washed into oxygenated $\mathrm{BSS}_{5.5}$ at $\mathrm{pH} 7.4$ and placed in the normoxic incubator for $24 \mathrm{hr}$ before $\mathrm{LDH}$ was measured or cells counted. $D$ indicates addition of $1 \mathrm{~mm}$ DIDS. Significant difference $(p<0.05)$ from $\mathrm{pH} 6.8$ alone is indicated by *; difference from $7.4-\mathrm{Na}$ is shown by \#. Vertical bars are means \pm SEM; $n=12-24$.

cDNA (Burnham et al., 1997) and identified two full-length cDNA clones. Both clones contained the same coding sequence but differed in the length of the untranslated regions. The 5' sequence of the cloned brain cDNAs was the same as that of the $\mathrm{NBC}$ variant recently identified in pancreas, with $98 \%$ identity at the amino acid level between the mouse and rat sequences (Abuladze et al., 1998). This variant differs from the kidney-derived $\mathrm{NBC}$ form in that the predicted N-terminal 41 residues of the kidney-expressed transporter are replaced by a different sequence of 85 residues. Because both variants also differ in their $5^{\prime}$ untranslated sequence, they seem to be generated by transcrip- 


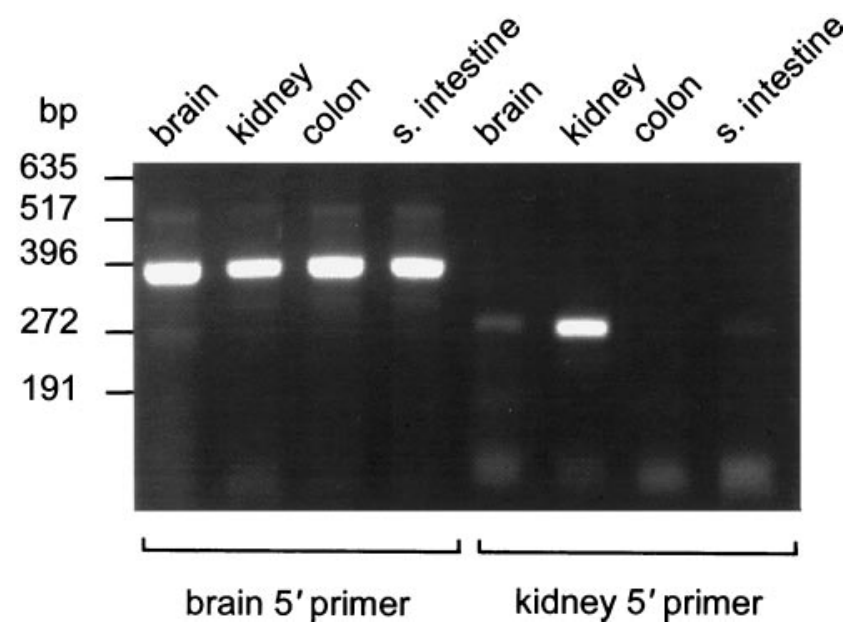

Figure 2. Amplification of splice variant-specific fragments from cDNA. PCR was performed with primers specific for either the brain or kidney sequence, using cDNA from brain, kidney, small intestine (s. intestine), or colon. The kidney-specific product is $258 \mathrm{bp}$; the brain-specific product is 372 bp. A negative control that lacked cDNA did not produce any amplification bands (data not shown).

tional initiation from different promoters of the NBC gene (Abuladze et al., 1998).

\section{Amplification of the two NBC splice variants from different tissues}

On the basis of the $5^{\prime}$ sequence difference in the NBC variants, two $5^{\prime}$-specific sense primers and a common antisense primer were designed to generate either a $258 \mathrm{bp}$ amplicon with the NBC sequence of kidney or a $372 \mathrm{bp}$ amplicon having the NBC sequence of brain. These primers were used on cDNA prepared from rat brain, kidney, small intestine, and colon RNA. We obtained strong amplification from kidney cDNA using the kidney-specific sense primer, weak amplification from brain and small intestine, and no amplification in colon cDNA (Fig. 2). In contrast, the primers for the brain and pancreas $\mathrm{NBC}$ variant amplified similar amounts from all sources of cDNA. Hence, the kidney form of NBC appears to have a more restricted expression than the form cloned from pancreas and brain.

\section{Functional expression of the brain-derived NBC cDNA}

The cloned full-length cDNA isolated from rat brain was placed in a eukaryotic expression vector under the control of the CMV promoter. Three days after nuclear injection of the recombinant vector into Xenopus oocytes, we measured currents after application of bicarbonate. The currents were dependent on extracellular sodium and blocked by DIDS (Fig. 3). Control oocytes injected with water showed no ion current on application of bicarbonate (data not shown). Physiological studies have shown previously NBC activity with a stoichiometry of either 2 or 3 bicarbonate ions per $\mathrm{Na}^{+}$. A transport ratio of 2:1 is thought to be associated with transport into the cell, leading to intracellular alkalinization. In cells in which the transporter is thought to run outward, acidifying the cell, the ratio was 3:1 (Newman, 1991). Although salamander retinal glial cells were reported to have 3:1 transport (Newman, 1991), rat hippocampal astrocytes and leech glial cells were shown to have 2:1 transport (Deitmer and Schlue, 1989; O'Connor et al., 1994). It was not possible to assess the transport ratio of the rat brain $\mathrm{NBC}$ in the Xenopus expression system.
A

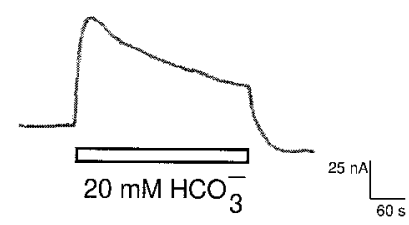

B

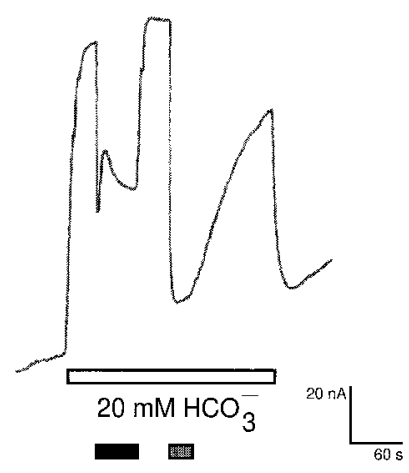

C

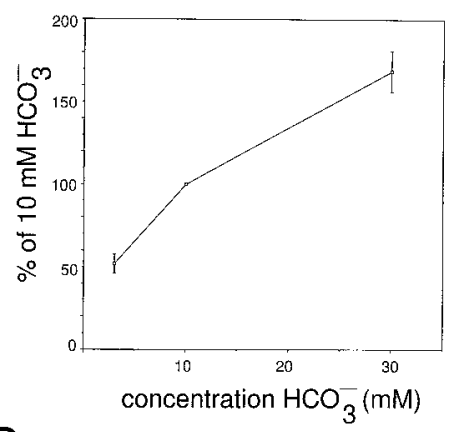

$\mathrm{D}$

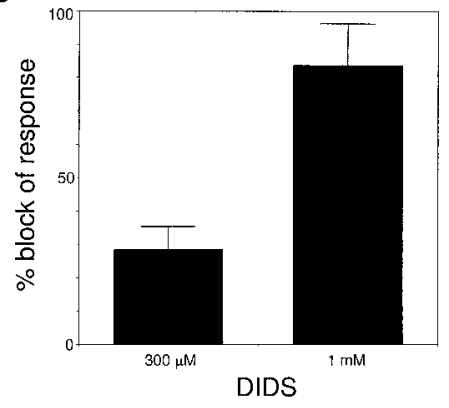

Figure 3. Expression of brain NBC in Xenopus oocytes leads to bicarbonate-inducible outward currents. $A$, An oocyte injected with NBC showed outward currents on application of bicarbonate, as indicated by the open horizontal bar. B, The bicarbonate-induced outward current was markedly reduced when external sodium was reduced from 130 to $20 \mathrm{~mm}$ (black horizontal bar) or when DIDS (1 mM) was applied (gray horizontal bar). $C$, The size of the outward current depends on the bicarbonate concentration. Amplitudes of the 3 and $30 \mathrm{~mm}$ bicarbonate-induced outward currents were normalized to that of the $10 \mathrm{~mm}$ bicarbonateinduced inward current $(n=3)$. $D$, Summary of the block of the bicarbonate-induced outward current by DIDS at $300 \mu \mathrm{M}(n=3)$ and 1 $\mathrm{mM}(n=3)$ is shown.

\section{Developmental expression pattern of NBC in brain}

Frozen sections from rat brain of the indicated ages were hybridized with an oligonucleotide probe (Fig. 4) that recognizes both known variants of NBC mRNA. No signal was obtained from embryonic day 11 (E11) embryos (data not shown), whereas a signal was obtained in spinal cord at E17 and in forebrain beginning at P0. Expression in brain was widespread and persisted throughout adulthood, although expression was highest at P15. The same developmental change in the expression of NBC was detected with a probe recognizing only the brain splice variant. Only extremely low expression levels could be detected in brain sections with a probe specific for the kidney form (data not shown), thus confirming the PCR results shown in Figure 2. For cellular resolution, the slides were emulsion-dipped, exposed for 6 weeks, developed, and counterstained. Regions from the hippocampus and cerebellum are shown in Figure 5. In the hippocampus, few grains are directly over the pyramidal neurons; rather the hybridization signal is present diff usely throughout the hippocampus. Often clusters of grains were observed between Purkinje cell bodies. Similarly, labeling in the cerebellum is consistent with expression in astrocytes and, in particular, in Bergman glia. Few grains are observed directly over the Purkinje cells. Double labeling with an antibody to glial fibrillary acidic protein allowed further confirmation of glial expression (Fig. $5 E, F)$. Our finding of $\mathrm{NBC}$ expression in astrocytes in the hip- 

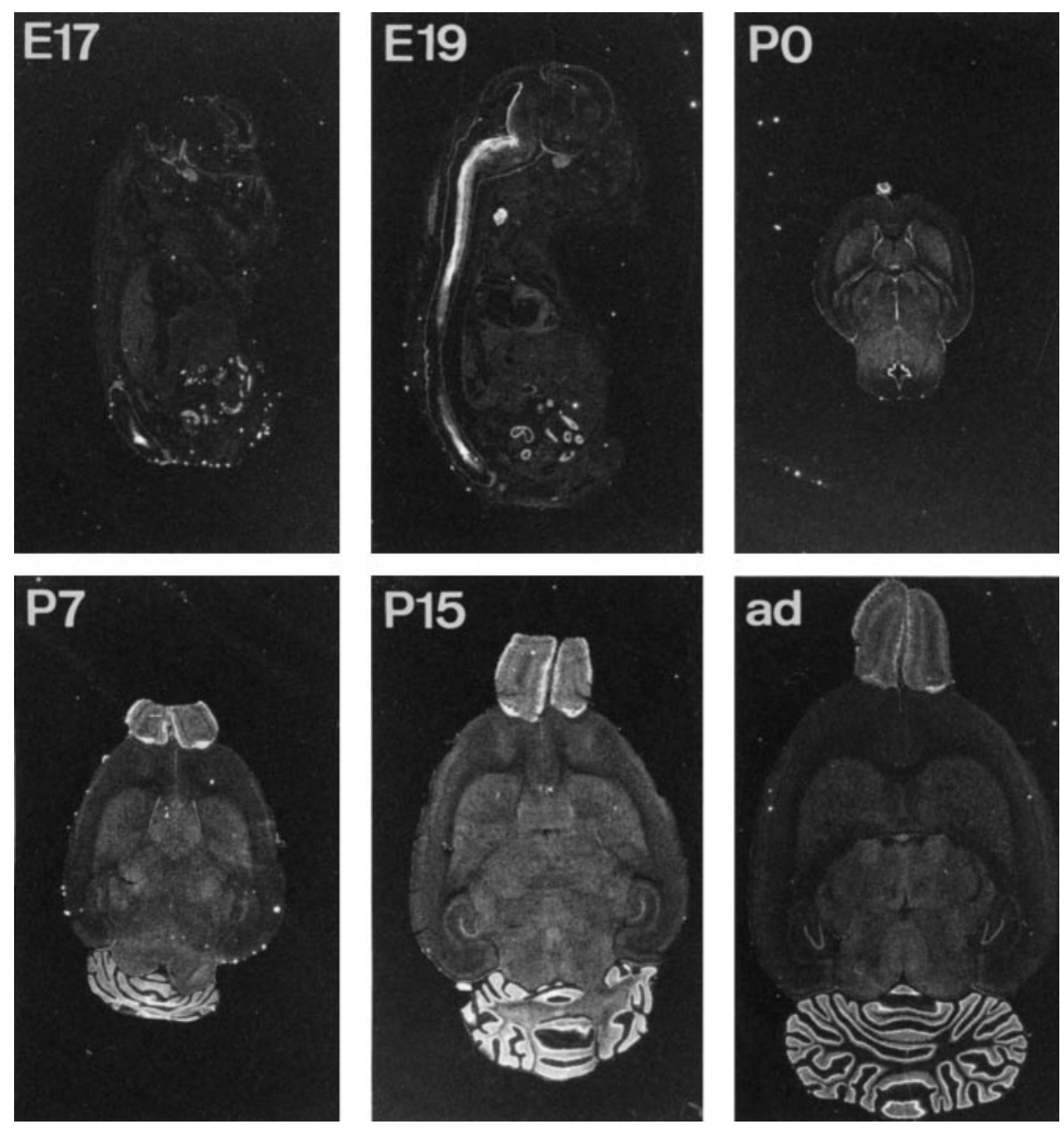

Figure 4. Developmental expression of NBC in rat brain. In situ hybridization was performed on frozen sections from rat brains of the indicated ages. Control sections hybridized with probe to which a 200 -fold excess of unlabeled probe was added showed essentially no signal (data not shown). ad, Adult. pocampus is consistent with the results of Grichtchenko and Chesler in gliotic hippocampal slice (Grichtchenko and Chesler, 1994).

\section{Overexpression of NBC in 3 T3 cells}

The mouse fibroblast cell line $3 \mathrm{~T} 3$ does not normally express much if any NBC, as shown by Western blots (Fig. $6 A$ ). We used this cell line to test the effect of overexpressing $\mathrm{NBC}$ on acid vulnerability. Either NBC or $\beta$-galactosidase as a control was stably expressed in $3 \mathrm{~T} 3$ cells using retroviral vectors. Sister cultures were exposed to $\mathrm{pH} 6.8$ for $24 \mathrm{hr}$. As seen in Figure 6, both sham-transfected and $\beta$-galactosidase-expressing 3T3 cells showed $15-20 \%$ cell death after $24 \mathrm{hr}$ in $\mathrm{BSS}_{5.5}$ at $\mathrm{pH} 6.8$ in the presence of both extracellular bicarbonate and sodium, whereas $\sim 40 \%$ of the NBC-overexpressing cells died, a significant increase in injury (Fig. $6 B$ ). Both removing bicarbonate and adding DIDS reduced the injury to background levels. An immunoblot using a polyclonal antibody to NBC shows the level of NBC expression obtained by retroviral transfection of 3T3 cells compared with controls (Fig. 6A). Morphological evidence of the difference in survival after exposure to $\mathrm{pH} 6.8$ was obtained by trypan blue staining (data not shown) and was in agreement with the levels of LDH release.

\section{DISCUSSION}

We have isolated a functional cDNA clone of the electrogenic sodium bicarbonate cotransporter from rat brain. This sequence is the same NBC variant recently identified from pancreas and differs in the $5^{\prime}$-untranslated and $\mathrm{N}$-terminal coding sequence from the NBC cDNA characterized previously from kidney. The transporter is electrogenic, requires sodium and bicarbonate, and is inhibited by DIDS, thus showing the principal characteristics of NBC. Extracellular pH 6.8 injury of primary cultured astrocytes requires extracellular sodium and bicarbonate and is also inhibited by DIDS. The association of NBC with acid sensitivity is underlined by the ability to confer acid sensitivity on $3 \mathrm{~T} 3$ cells by overexpressing NBC.

The immediate response of $\mathrm{NBC}$ to lowering extracellular bicarbonate and $\mathrm{pH}$ is to run in the outward direction (Munsch and Deitmer, 1994) acidif ying intracellular $\mathrm{pH}$, but there were no previous studies on the function of the transporter in the setting of prolonged reduction of extracellular bicarbonate at $\mathrm{pH} \mathrm{6.8,} \mathrm{as}$ studied here. We demonstrate that the intracellular $\mathrm{pH}$ measured with BCECF in the presence of extracellular bicarbonate is higher than that in its absence, after $3 \mathrm{hr}$ at extracellular $\mathrm{pH}$ 6.8. This is consistent with the transporter running in the inward direction after equilibration to the new buffer condition. The severity of intracellular acidosis did not correlate with injury. Protection of astrocytes from ischemia-like injury by DIDS is thus reminiscent of the response of myocardial cells. Inhibition of intracellular alkalinization by inhibition either of the sodium hydrogen exchanger or of bicarbonate transport has been shown to be highly protective in the setting of myocardial ischemia (Karmazyn, 1998). In the case of myocardial ischemia too rapid alkalinization of intracellular $\mathrm{pH}$ is associated with a worse outcome. 
Figure 5. Cellular resolution of hybridization signal. Emulsion-dipped sections from P15 rats were exposed for 6 weeks and then developed and counterstained. Regions from the hippocampus $(A, C)$ and the cerebellum $(B, D)$ are shown at two magnifications. Dark-field photomicrographs show the hybridization signal as white dots $(A, B)$, whereas bright field shows the hybridization signal as dark dots $(C, D)$. $A, C$, Labeling in the hippocampus reveals a lack of association of the hybridization grains with neurons. Arrowheads in $C$ indicate clusters of grains between pyramidal neuronal cell bodies. $B, D$, Labeling in the cerebellum is consistent with expression in astrocytes and in particular in Bergman glia. Few grains are observed directly over the Purkinje cells indicated by arrowheads in $D$. The fields were photographed with a $10 \times$ and $40 \times$ objective using a Zeiss axioplan microscope. $D G$, Dentate gyrus; $g r$, granular layer; mol, molecular layer; $p$, Purkinje cell layer; $s o$, stratum oriens; $s p$, stratum pyramidale; $s r$, stratum radiatum. $E, F$, To confirm the identity of the hybridizing cells, double labeling was performed using antiGFAP antibody to identify astrocytes on the same section that was hybridized with a digoxigenin-labeled probe for NBC. An area from the cerebellum is shown; arrowheads indicate individual cells showing both cytoplasm immunoreactivity for GFAP $(E)$ and a hybridization signal to the riboprobe for NBC $(F)$. $G L$, granular layer; $M L$, molecular layer; $P L$, Purkinje layer. Similar sections stained only for GFAP showed the same pattern of staining (data not shown).
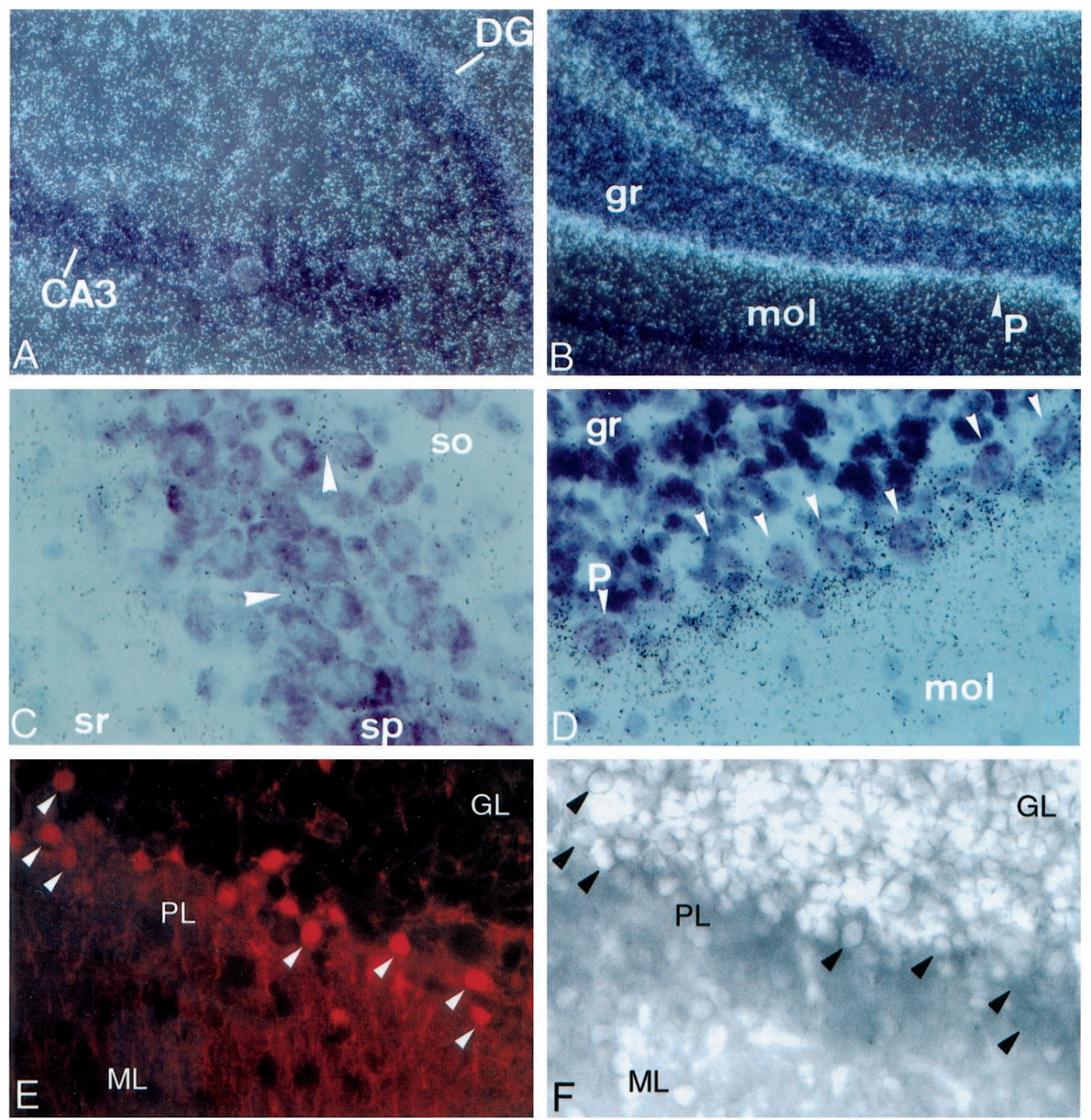

Protection by reducing extracellular sodium may at first be surprising, because a variety of transporters depend on the sodium gradient for their normal function. However, sodium overload has been shown to contribute to anoxic neuronal injury, and substitution for $\mathrm{Na}^{+}$with an impermeant ion was protective (Friedman and Haddad, 1994a). Elevation of intracellular $\mathrm{Na}^{+}$is thought to contribute to reversal of $\mathrm{Na}^{+} / \mathrm{Ca}^{2+}$ exchange and to worsen calcium overload. Although the mechanism of astrocyte injury induced by lowering medium $\mathrm{pH}$ to 6.8 is not known, it is possible that sodium overload contributes to the injury. Prolonged sodium influx could contribute to calcium overload by reversal of $\mathrm{Na}^{+} / \mathrm{Ca}^{2+}$ exchange and contribute to energy depletion by chronic activation of the $\mathrm{Na}^{+} / \mathrm{K}^{+}$ATPase. The $\mathrm{Na}^{+} / \mathrm{K}^{+}$ ATPase has been reported to saturate above intracellular $\mathrm{Na}^{+}$ concentrations of $30 \mathrm{~mm}$ (Collins et al., 1992), and intracellular $\mathrm{Na}^{+}$concentrations above $50 \mathrm{~mm}$ have been reported in anoxic neurons in vitro (Friedman and Haddad, 1994b).

While this work was in progress, the N-terminal NBC variant identified by us in brain was reported from pancreas (Abuladze et al., 1998). The Northern analysis presented by Abuladze et al. (1998) and our RT-PCR data agree in finding this splice variant in many tissues, whereas the kidney splice variant is restricted primarily to kidney. Two variants with different N-terminal sequences allow for differential functional regulation, possibly by phosphorylation (Abuladze et al., 1998). The different N-terminal sequences in the two NBC forms may also allow for association with different intracellular or membrane proteins. In the case of the anion exchanger AE1, sorting to the plasma membrane or retention in intracellular membranes is determined by the $\mathrm{N}$-terminal sequence (Cox et al., 1995). Finally, the N-terminal sequences could determine the formation of heteromeric transporters, if indeed the transporter is a functional multimer.

Physiological studies of NBC in different cell types and species have demonstrated that it can transport either two or three bicarbonate ions per sodium ion. It is intriguing to ask whether the different ratios observed physiologically reflect expression of different genes or regulation of a single transporter. The existence of the NBC variants suggests the possibility of differences in function being specified at the level of promoter choice or splice variation. Further studies and possible identification of additional bicarbonate transporters will be needed to answer this question.

In situ hybridization shows that the transporter is expressed throughout the brain, beginning at approximately the time of birth and persisting throughout adulthood. The primarily late developmental expression suggests that this transporter is critical during the later stages of brain development. It is expressed during the time of generation and maturation of astrocytes. Appropriate regulation of both intracellular and extracellular $\mathrm{pH}$ may be increasingly important with brain maturation, accounting for the time course of expression of this protein. That it is widely distributed throughout the brain suggests it serves a basic function in all brain regions. It is likely that proper functioning of the 

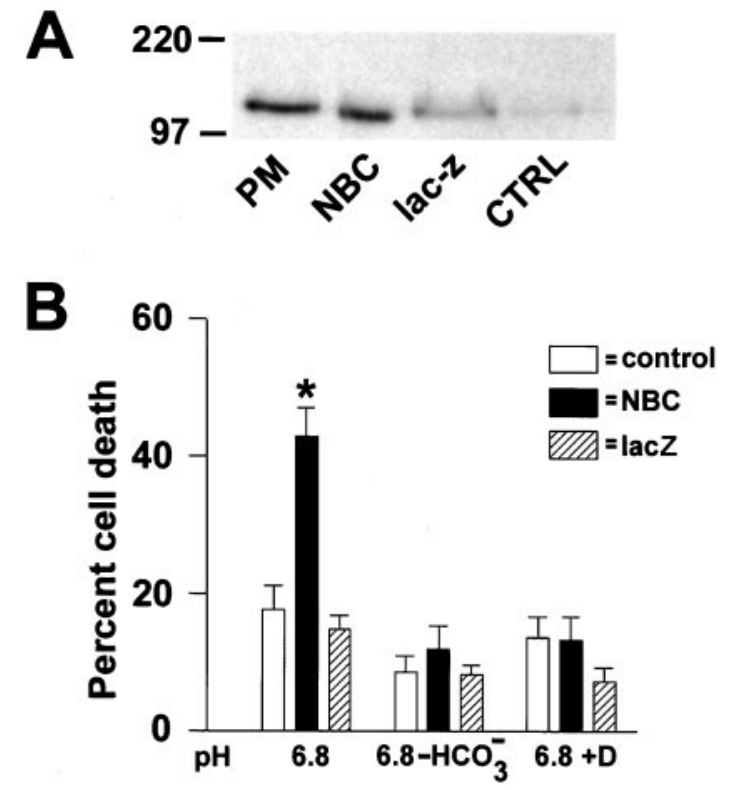

Figure 6. A, Little NBC is detected by immunoblot in 3 T3 cells $(C T R L)$, whereas retroviral expression of $\mathrm{NBC}$ induces a large increase in the immunoreactive band for NBC. Purified brain plasma membrane $(P M)$ is shown in the first lane as a positive control, followed by NBC-expressing $3 \mathrm{~T} 3$ cells $(N B C), \beta$-galactosidase-expressing $3 \mathrm{~T} 3$ cells (lac Z), and control 3T3 cells. Equal amounts of protein were loaded. B, Overexpression of NBC renders 3 T3 cells vulnerable to acid injury. Untransfected and control $\beta$-galactosidase-expressing $3 \mathrm{~T} 3$ cultures exposed to $\mathrm{BSS}_{5.5}$ at $\mathrm{pH}$ 6.8 for $24 \mathrm{hr}$ showed little injury, whereas $3 \mathrm{~T} 3$ cells overexpressing NBC suffered $\sim 40 \%$ cell death. Substituting for bicarbonate or adding $1 \mathrm{~mm}$ DIDS significantly reduced the injury of NBC-overexpressing cells. * indicates significant difference from control and lacZ; $p<0.05$; $n=10-16$.

$\mathrm{pH}$ regulatory $\mathrm{NBC}$ transporter is important to proper neuronal function, although the transporter appears to be present primarily in glial cells. The expression of NBC may contribute to the different patterns of injury caused by ischemia in the perinatal period compared with the adult. Astrocyte development in the brain may also impact the outcome from ischemia.

Astrocytes are now known to perform many essential functions including modulating neuronal excitability (Ransom, 1992), regulating the extracellular concentrations of ions (Newman, 1995) and neurotransmitters (Schousboe and Westergaard, 1995), providing a critical metabolic link between the blood supply and neurons (Tsacopoulos and Magistretti, 1996), and protecting neurons from excitotoxic (Rosenberg and Aizenman, 1989; Dugan et al., 1995) and oxidative injury (Raps et al., 1989; Sagara et al., 1993; Desagher et al., 1996). Thus neuronal function and survival are inextricably linked to glial function and survival. Preventing glial impairment is highly likely to contribute to improved neuronal survival during in vivo ischemia. The identification of the sodium/bicarbonate cotransporter as participating in astrocyte injury provides a novel target for brain protective strategies. This is the first glial-specific mechanism of injury to be identified. To test directly the role of $\mathrm{NBC}$ on the outcome from cerebral ischemia will require changing the level of $\mathrm{NBC}$ expression in astrocytes in vivo. Much as the idea of excitotoxicity suggested a variety of strategies to block neuron-specific injury, it may now be possible to target glial-specific injury mechanisms.

\section{REFERENCES}

Abuladze N, Lee I, Newman D, Hwang J, Boorer K, Pushkin A, Kurtz I (1998) Molecular cloning, chromosomal localization, tissue distribution, and functional expression of the human pancreatic sodium bicarbonate cotransporter. J Biol Chem 273:17689-17695.

Bing OH, Brooks WW, Messer JV (1973) Heart muscle viability following hypoxia: protective effect of acidosis. Science 180:1297-1298.

Burnham CE, Amlal H, Wang Z, Shull GE, Soleimani M (1997) Cloning and functional expression of a human kidney $\mathrm{Na}+\mathrm{HCO}-$ cotransporter. J Biol Chem 272:19111-19114.

Catania MV, Tolle TR, Monyer H (1995) Differential expression of AMPA receptor subunits in NOS-positive neurons of cortex, striatum, and hippocampus. J Neurosci 15:7046-7061.

Collins A, Somlyo AV, Hilgemann DW (1992) The giant cardiac membrane patch method: stimulation of outward $\mathrm{Na}(+)-\mathrm{Ca} 2+$ exchange current by MgATP. J Physiol (Lond) 454:27-57.

Cox KH, Adair-Kirk TL, Cox JV (1995) Four variant chicken erythroid AE1 anion exchangers. Role of the alternative $\mathrm{N}$-terminal sequences in intracellular targeting in transfected human erythroleukemia cells. J Biol Chem 270:19752-19760.

Currin RT, Gores GJ, Thurman RG, Lemasters JJ (1991) Protection by acidotic $\mathrm{pH}$ against anoxic cell killing in perfused rat liver: evidence for a $\mathrm{pH}$ paradox. FASEB J 5:207-210.

Deitmer JW, Schlue WR (1989) An inwardly directed electrogenic sodium-bicarbonate co-transport in leech glial cells. J Physiol (Lond) 411:179-194.

Desagher S, Glowinski J, Premont J (1996) Astrocytes protect neurons from hydrogen peroxide toxicity. J Neurosci 16:2553-2562.

Dugan LL, Bruno VMG, Amagasu SM, Giffard RG (1995) Glia modulate the response of murine cortical neurons to excitotoxicity: glia exacerbate AMPA neurotoxicity. J Neurosci 15:4545-4555.

Friedman JE, Haddad GG (1994a) Removal of extracellular sodium prevents anoxia-induced injury in freshly dissociated rat CA1 hippocampal neurons. Brain Res 641:57-64.

Friedman JE, Haddad GG (1994b) Anoxia induces an increase in intracellular sodium in rat central neurons in vitro. Brain Res 663:329-334.

Giffard RG, Monyer H, Christine CW, Choi DW (1990a) Acidosis reduces NMDA receptor activation, glutamate neurotoxicity, and oxygen-glucose deprivation neuronal injury in cortical culture. Brain Res 506:339-342.

Giffard RG, Monyer H, Choi DW (1990b) Selective vulnerability of cultured cortical glia to injury by extracellular acidosis. Brain Res 530:138-141.

Grichtchenko II, Chesler M (1994) Depolarization-induced alkalinization of astrocytes in gliotic hippocampal slices. Neuroscience 62:1071-1078.

Karmazyn M (1998) The myocardial sodium-hydrogen exchanger (NHE) and its role in mediating ischemic and reperfusion injury. Keio J Med 47:65-72.

Koh JY, Choi DW (1987) Quantitative determination of glutamate mediated cortical neuronal injury in cell culture by lactate dehydrogenase efflux assay. J Neurosci Methods 20:83-90.

Koike A, Akita T, Hotta Y, Takeya K, Kodama I, Murase M, Abe T, Toyama J (1996) Protective effects of dimethyl amiloride against postischemic myocardial dysfunction in rabbit hearts: phosphorus 31nuclear magnetic resonance measurements of intracellular $\mathrm{pH}$ and cellular energy. J Thorac Cardiovasc Surg 112:765-775.

Kopito RR (1990) Molecular biology of the anion exchanger gene family. Int Rev Cytol 123:177-199.

Kraig RP, Pulsinelli WA, Plum F (1986) Carbonic acid buffer changes during complete brain ischemia. Am J Physiol 250:R348-R357.

Lascola C, Kraig RP (1997) Astroglial acid-base dynamics in hyperglycemic and normoglycemic global ischemia. Neurosci Biobehav Rev 21:143-150.

Mann R, Mulligan RC, Baltimore D (1983) Construction of a retrovirus packaging mutant and its use to produce helper-free defective retrovirus. Cell 33:153-159.

Meiltz A, Kucera P, de Ribaupierre Y, Raddatz E (1998) Inhibition of bicarbonate transport protects embryonic heart against reoxygenationinduced dysfunction. J Mol Cell Cardiol 30:327-335.

Mellergard P, Ouyang YB, Siesjo BK (1994) The regulation of intracellular $\mathrm{pH}$ is strongly dependent on extracellular $\mathrm{pH}$ in cultured rat astrocytes and neurons. Acta Neurochir Suppl (Wien) 60:34-37.

Miller AD, Rosman GJ (1989) Improved retroviral vectors for gene transfer and expression. Biotechniques 7:980-988. 
Monyer H, Seeburg PH, Wisden W (1991) Glutamate-operated channels: developmentally early and mature forms arise by alternative splicing. Neuron 6:799-810.

Munsch T, Deitmer JW (1994) Sodium-bicarbonate cotransport current in identified leech glial cells. J Physiol (Lond) 474:43-53.

Myers RE, Yamaguchi S (1977) Nervous system effects of cardiac arrest in monkeys. Arch Neurol 34:65-74.

Newman EA (1991) Sodium-bicarbonate cotransport in retinal Muller (glial) cells of the salamander. J Neurosci 11:3972-3983.

Newman EA (1995) Glial cell regulation of extracellular potassium. In: Neuroglia (Kettenmann H, Ransom B, eds), pp 717-731. New York: Oxford UP.

O'Connor ER, Sontheimer H, Ransom BR (1994) Rat hippocampal astrocytes exhibit electrogenic sodium-bicarbonate co-transport. J Neurophysiol 72:2580-2589.

Papadopoulos MC, Sun X-Y, Cao J, Mivechi NF, Giffard RG (1996) Overexpression of HSP-70 protects astrocytes from combined oxygenglucose deprivation. NeuroReport 7:429-432.

Pentilla A, Trump BF (1974) Extracellular acidosis protects Ehrlich ascites tumor cells and rat renal cortex against anoxic injury. Science 185:277-278.

Ransom B (1992) Glial modulation of neural excitability mediated by extracellular pH: a hypothesis. Prog Brain Res 94:37-46.

Raps SP, Lai JC, Hertz L, Cooper AJ (1989) Glutathione is present in high concentrations in cultured astrocytes but not in cultured neurons. Brain Res 493:398-401.

Romero MF, Boron WF (1999) Electrogenic Na+/HCO3- cotransporters: cloning and physiology. Annu Rev Physiol 61:699-723.

Romero MF, Hediger MA, Boulpaep EL, Boron WF (1997) Expression cloning and characterization of a renal electrogenic $\mathrm{Na}^{+} / \mathrm{HCO}_{3}-\mathrm{co}-$ transporter. Nature 387:409-413.
Romero MF, Fong P, Berger UV, Hediger MA, Boron WF (1998) Cloning and functional expression of $\mathrm{rNBC}$, an electrogenic $\mathrm{Na}(+)-$ HCO3 - cotransporter from rat kidney. Am J Physiol 274:F425-F432.

Rosenberg PA, Aizenman E (1989) Hundred-fold increase in neuronal vulnerability to glutamate toxicity in astrocyte-poor cultures of rat cerebral cortex. Neurosci Lett 103:162-168.

Sagara JI, Miura K, Bannai S (1993) Maintenance of neuronal glutathione by glial cells. J Neurochem 61:1672-1676.

Schousboe A, Westergaard N (1995) Transport of neuroactive amino acids in astrocytes. In: Neuroglia (Kettenmann H, Ransom B, eds), pp 246-258. New York: Oxford UP.

Schurr A, Dong WQ, Reid KH, West CA, Rigor BM (1988) Lactic acidosis and recovery of neuronal function following cerebral hypoxia in vitro. Brain Res 438:311-314.

Schurr A, Payne RS, Miller JJ, Rigor BM (1997) Brain lactate is an obligatory aerobic energy substrate for functional recovery after hypoxia: further in vitro validation. J Neurochem 69:423-426.

Tombaugh GC, Sapolsky RM (1990) Mild acidosis protects hippocampal neurons from injury induced by oxygen and glucose deprivation. Brain Res 506:343-345.

Trapp S, Luckermann M, Brooks PA, Ballanyi K (1996) Acidosis of rat dorsal vagal neurons in situ during spontaneous and evoked activity. J Physiol (Lond) 496:695-710.

Tsacopoulos M, Magistretti PJ (1996) Metabolic coupling between glia and neurons. J Neurosci 16:877-885.

Zwart R, Oortgiesen M, Vijverberg HP (1995) Differential modulation of alpha 3 beta 2 and alpha 3 beta 4 neuronal nicotinic receptors expressed in Xenopus oocytes by flufenamic acid and niflumic acid. J Neurosci 15:2168-2178. 